\title{
Growth and development of Argulus coregoni (Crustacea: Branchiura) on salmonid and cyprinid hosts
}

\author{
A. Pasternak ${ }^{1, *}$, V. Mikheev ${ }^{2}$, E. T. Valtonen ${ }^{3}$ \\ ${ }^{1}$ Institute of Oceanology, Russian Academy of Sciences, 36 Nakhimovskii Prospekt, Moscow 117997, Russia \\ ${ }^{2}$ Institute of Ecology and Evolution, Russian Academy of Sciences, 33 Leninskii Prospekt, Moscow 119071, Russia \\ ${ }^{3}$ Department of Environmental and Biological Science, University of Jyväskylä, PL 35, 40351 Jyväskylä, Finland
}

\begin{abstract}
The obligate fish ectoparasite Argulus coregoni is strictly specific to salmonids and is very rarely found on other fish species. The ability of the parasite to grow and complete its life cycle on a cyprinid host, Rutilus rutilus, was compared with that on a typical salmonid host, Oncorhynchus mykiss. Rearing experiments were run for $42 \mathrm{~d}$ with newly hatched metanauplii in flow-through tanks. Body length and sex of the parasites were recorded every $5 \mathrm{~d}$. Growth rates on O. mykiss exceeded those on $R$. rutilus from the age of $2 \mathrm{wk}$, at which time the parasites reached a length of about $3.5 \mathrm{~mm}$. Males grew faster than females at the beginning of the experiment up to a length of 2.5 to $3.0 \mathrm{~mm}$; thereafter, a faster growth rate was observed in females. In another experiment, association of parasites with the hosts was monitored and residence time defined as the period between attachment and first detachment from the host. Longer residence time was observed on O. mykiss than on $R$. rutilus; female parasites stayed on both fish species longer than did males. Faster growth of parasites could be associated with longer uninterrupted periods of attachment to hosts, since frequent detachment means higher energy losses and less time available for feeding. Despite its slower growth on $R$. rutilus, $A$. coregoni matured and laid egg clutches, but took $5 \mathrm{~d}$ longer than on $O$. mykiss. The potential of $A$. coregoni to complete its life cycle on cyprinids could have important ecological consequences, creating an infection reservoir when the main salmonid hosts are rare or temporarily missing.
\end{abstract}

KEY WORDS: Growth rate $\cdot$ Ectoparasite $\cdot$ Argulus coregoni $\cdot$ Host suitability

\section{INTRODUCTION}

Growth and fecundity of any given parasite vary among its host species (Poulin 1996). There may be a trade-off between the ability to use many host species and the average fitness achieved on these hosts. Extreme adaptation to one host species can usually be achieved only at the expense of adaptations to other host species (Fry 1990). Required, suitable, or unsuitable hosts for a certain parasite are distinguished according to their ability to maintain the parasite population (Holmes 1979).

In the lakes and fish farms of Central Finland, 2 closely related species of fish ectoparasites, Argulus coregoni Thorell and A. foliaceus L., co-exist. In con- trast to the temperate $A$. foliaceus, which is generally specific to various fish species (Kollatsch 1959, Valtonen et al. 1997, Pasternak et al. 2000), the boreal A. coregoni is highly specific to salmonids (Stammer 1959, Shimura 1983). However, occasional findings of A. coregoni on other fishes, including cyprinids, have been reported (Stammer 1959, Lester \& Roubal 1995).

The reason for the higher occurrence of Argulus coregoni on salmonid compared to cyprinid hosts is unknown. It could be due to an 'encounter filter', i.e. partial segregation on ecological and/or ethological scales, or to a 'compatibility filter', i.e. differential suitability of the hosts through physiological or immunological factors (Combes 1991). One of the mechanisms 
responsible for such differential suitability may be the difference in residence time (time from attachment of a parasite to first detachment), which was found to be variable in A. foliaceus (Pasternak et al. 2000). To test whether residence time of $A$. coregoni on different hosts differs, we monitored the activity (attachment and detachment) of the parasite infecting salmonid and cyprinid hosts. Our main aim was to clarify whether a cyprinid fish could serve as a suitable host for $A$. coregoni, i.e. if the parasite can grow on it and produce eggs. To test this, newly hatched $A$. coregoni were reared on 2 host species, rainbow trout Oncorhynchus mykiss and roach Rutilus rutilus, under identical conditions.

\section{MATERIALS AND METHODS}

Experimental animals. Stones bearing overwintered egg clutches of Argulus coregoni were collected from a flow-through canal at a large commercial fish farm in Central Finland on 30 May 2002. The stones were placed in the laboratory in shallow, white plastic tanks with filtered lake water at $17.8^{\circ} \mathrm{C}$ and $400 \mathrm{~lx}$. On the following day the eggs started to hatch. Metanauplii were collected with pipettes the day after hatching and kept in filtered water for $5 \mathrm{~h}$ until the start of the rearing experiment.

Rainbow trout of 15 to $20 \mathrm{~cm}$ total length were collected from the rearing ponds of the farm and roach of 14 to $20 \mathrm{~cm}$ total length from an adjacent canal supplying water to the farm. Prior to experiments, all fishes were thoroughly examined for ectoparasites.

Experimental design. We set up 2 identical flowthrough systems comprising five $30 \mathrm{l}$ dark-green plastic tanks each. Filtered lake water was pumped into a large plastic tank from which it was distributed among the experimental tanks. Of the 10 experimental tanks, 5 contained 5 rainbow trout each, while the other 5 tanks contained 5 roach each. The positions of the tanks were random. Water inflow was near the bottom of the tanks; outflow windows near the top were covered with $200 \mu \mathrm{m}$ mesh to prevent parasites escaping. The tanks were covered with nets to prevent fish from jumping out. Water temperature varied from 16.9 to $20.3^{\circ} \mathrm{C}$ in accordance with the ambient temperature fluctuations during the experimental period (1 June to 12 July 2002).

Growth on different host species: On 1 June, we released 200 metanauplii of $1 \mathrm{~d}$ old into each of the 10 rearing tanks containing 5 fish per tank. The body length of 50 newly hatched Argulus coregoni was measured under a dissecting microscope as the distance between the anterior edge of the carapace and the posterior end of the caudal rami. To facilitate measurement, parasites were immobilised with carbonated water. They recovered from this treatment within a few minutes. The duration of the rearing experiment was $42 \mathrm{~d}$. Every 5 th day, about 100 parasites (approximately 10 from each tank) were taken from both the rainbow trout and roach and measured (see Table 1). For this purpose, 2 fish from each tank were caught at random and transferred to a white plastic basin, where parasites were gently removed manually from the fish. The fish and measured parasites were returned to the same tanks. If a fish died during the experiment, it was replaced by a new fish of the same size and species. At the end of the experiment, we collected all parasites from all hosts. The sexes were distinguished by morphology of the abdomen starting at the age of $6 \mathrm{~d}$ ( 6 June). The size-frequency distributions of the parasites were checked for normality and homogeneity of variances for all samples, and a 1-way ANOVA was used for comparisons at each sampling date to test the effects of hosts and parasite sex on growth. To assess specific growth rate, the difference in mean body length between 2 consecutive dates was divided by the mean length at the beginning of the $5 \mathrm{~d}$ period and expressed as percent.

Attachment and detachment of parasites: Experiments to determine attachment and detachment times of Argulus coregoni were carried out on males and females separately. Adult males $(\mathrm{n}=48$, mean size $\pm \mathrm{SD}$ $=8.4 \pm 0.79 \mathrm{~mm})$ and females $(\mathrm{n}=48,8.0 \pm 0.92 \mathrm{~mm})$ were studied in 16 dark plastic boxes, each containing 151 of water. A rainbow trout was placed in each of 8 boxes and a roach in each of the remaining 8 boxes. Experiments were conducted at $19.1^{\circ} \mathrm{C}$ and $300 \mathrm{~lx}$. We released 6 A. coregoni males into each of 4 boxes with rainbow trout and into 4 boxes with roach, and 6 females into each of the other 8 boxes containing rainbow trout or roach. Parasites were starved for $1 \mathrm{~d}$ prior to the experiment. The number of attached A. coregoni was determined every $10 \mathrm{~min}$, and the time between release and first attachment ( $t_{\mathrm{at}}$, min) was recorded for each parasite. Argulids which did not attach within $2.5 \mathrm{~h}$ were removed. Detachment was recorded as the appearance of free-swimming parasites (see Table 3). The boxes were checked each hour for $12 \mathrm{~h}$, and detached $A$. coregoni removed. The residence time on a host $\left(t_{\text {res }}, \mathrm{h}\right)$ was assessed for each parasite as the interval between attachment and detachment. Those parasites that had not detached by the end of the experiment were considered to have a residence time of $12 \mathrm{~h}$. Attachment and detachment times were underestimated (not all of the parasites had attached and detached by the end of the respective observations), and were used only as rank indices for comparing the behaviour of males and females, or the behaviour of parasites on different hosts. Due to the skewed distribution of the data on $t_{\text {at }}$ and $t_{\text {res, }}$ a non-parametric KruskalWallis ANOVA was used for comparisons. 
Table 1. Argulus coregoni. Number of males and females from different hosts (rainbow trout Oncorhynchus mykiss and roach Rutilus rutilus), measured during the growth experiment. Sexes were not distinguished at the start of the experiment on 1 June 2002. (days): days from beginning of experiment

\begin{tabular}{|lcccc|}
\hline \multirow{2}{*}{$\begin{array}{l}\text { Date } \\
\text { (days) }\end{array}$} & \multicolumn{2}{c}{$\begin{array}{c}\text { On rainbow trout } \\
\text { Males }\end{array}$} & Females & \multicolumn{2}{c|}{$\begin{array}{c}\text { On roach } \\
\text { Males }\end{array}$} & Females \\
\hline 1 June (0) & - & - & - & - \\
6 June (5) & 30 & 27 & 34 & 32 \\
11 June (10) & 55 & 35 & 44 & 34 \\
16 June (15) & 52 & 50 & 50 & 40 \\
21 June (20) & 63 & 57 & 60 & 60 \\
27 June (26) & 67 & 56 & 44 & 51 \\
2 July (32) & 60 & 59 & 42 & 40 \\
7 July (37) & 55 & 48 & 23 & 25 \\
12 July (42) & 130 & 111 & 16 & 17 \\
& & & & \\
\hline
\end{tabular}

\section{RESULTS}

Only 241 parasites remained on rainbow trout and 33 on roach after $42 \mathrm{~d}$ (Table 1 ). The ratio of females to males was close to 1:1 for the whole experiment. Argulus coregoni grew to adulthood and produced eggs on both rainbow trout and roach (Fig. 1). Their sizes and
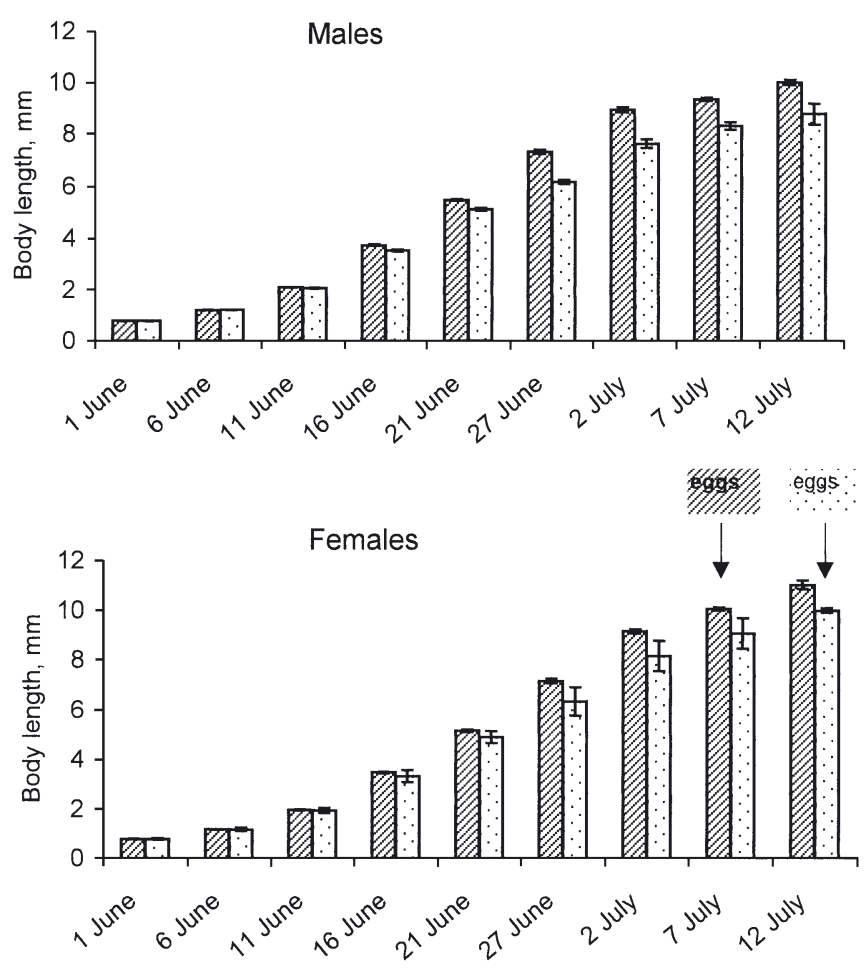

Fig. 1. Argulus coregoni. Growth (mean $\pm \mathrm{SE}$ ) of males and females on rainbow trout Oncorhynchus mykiss (hatched bars) and roach Rutilus rutilus (stippled bars). Arrows indicate dates when first egg clutches were found
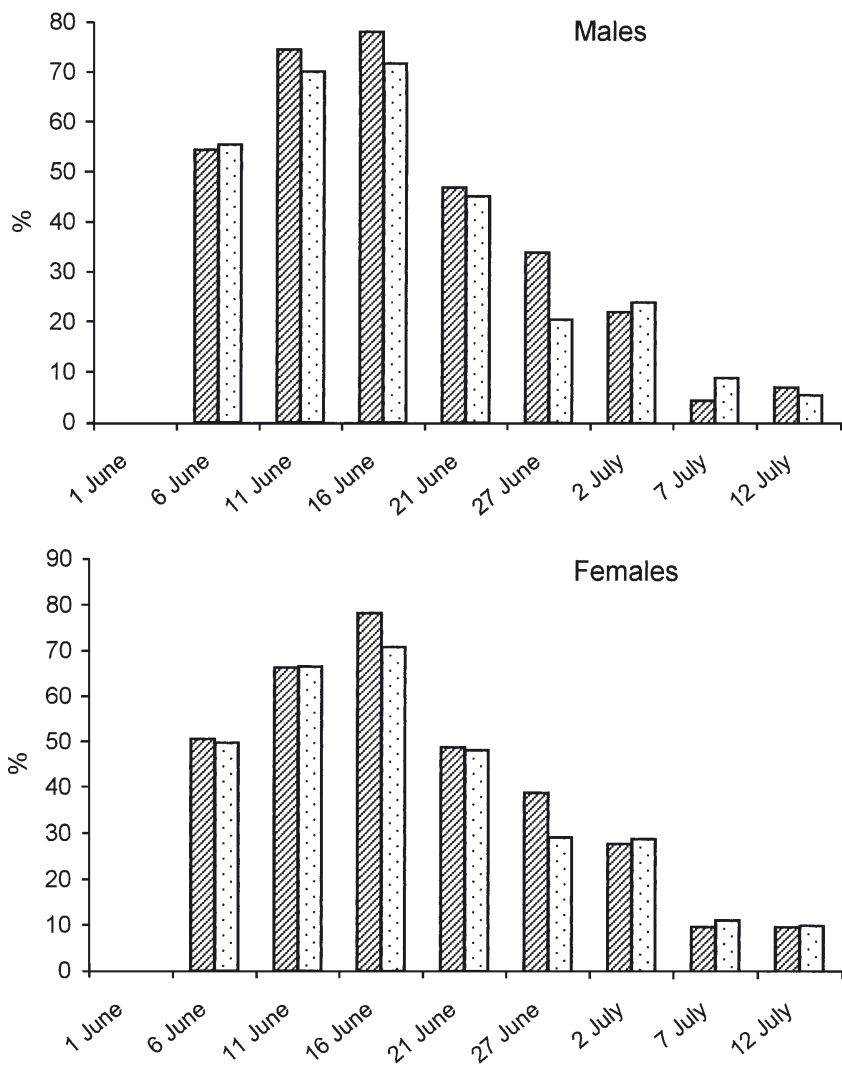

Fig. 2. Argulus coregoni. Specific growth rates (difference in mean body length over a $5 \mathrm{~d}$ period divided by body length at beginning of this period, expressed as \%) of males and females on rainbow trout Oncorhynchus mykiss (hatched bars) and roach Rutilus rutilus (stippled bars)

growth rates on both host species did not differ until the end of the first week. Thereafter, growth on the rainbow trout exceeded that on the roach (Figs. $1 \& 2$ ), with both males and females being significantly larger in size on the rainbow trout from the third week onwards until the end of the experiment (Table 2). The first egg clutches were laid 37 and $42 \mathrm{~d}$ after release of metanauplii in the tanks with rainbow trout and roach, respectively (Fig. 1).

Females and males were of equal size during the first week of rearing on both fish species. Thereafter, males grew significantly faster on both roach and rainbow trout until the middle of the fourth week, when they reached a length of 6 to $7 \mathrm{~mm}$. The trend then changed, with females growing faster and reaching a larger size on both host species (Figs. 1 \& 2, Table 2). On the whole, sexual dimorphism in the growth patterns of parasites was similar on roach and rainbow trout.

Almost all released parasites attached to the rainbow trout within $2.5 \mathrm{~h}$, and most attached also to the roach (Table 3). Some parasites (15\%) had not attached by 
Table 2. Argulus coregoni. Growth of males (M) and females (F) on rainbow trout Oncorhynchus mykiss and roach Rutilus rutilus. Pairwise statistical comparisons (1-way ANOVA) for each sampling date. Sexes were not distinguished on 1 June

\begin{tabular}{|c|c|c|c|c|c|c|c|c|}
\hline \multirow[t]{2}{*}{$\begin{array}{l}\text { Date } \\
(2002)\end{array}$} & \multicolumn{2}{|c|}{$\begin{array}{c}\text { F on trout } \\
\text { vs } F \text { on roach }\end{array}$} & \multicolumn{2}{|c|}{$\begin{array}{c}\mathrm{M} \text { on trout } \\
\text { vs } \mathrm{M} \text { on roach }\end{array}$} & \multicolumn{2}{|c|}{$\begin{array}{l}\text { F vs M } \\
\text { on trout }\end{array}$} & \multicolumn{2}{|c|}{$\begin{array}{l}\text { F vs M } \\
\text { on roach }\end{array}$} \\
\hline & $F$ & $\mathrm{p}$ & $F$ & $\mathrm{p}$ & $F$ & $\mathrm{p}$ & $F$ & $\mathrm{p}$ \\
\hline 1 June & - & - & - & - & - & - & - & - \\
\hline 6 June & 0.089 & 0.7667 & 0.244 & 0.6235 & 3.292 & 0.0782 & 5.762 & 0.0200 \\
\hline 11 June & 0.080 & 0.7781 & 3.538 & 0.0631 & 39.083 & 0.0000 & 21.153 & 0.0000 \\
\hline 16 June & 9.639 & 0.0026 & 16.092 & 0.0001 & 32.632 & 0.0000 & 15.017 & 0.0002 \\
\hline 21 June & 20.041 & 0.0000 & 31.583 & 0.0000 & 15.741 & 0.0000 & 11.984 & 0.0007 \\
\hline 27 June & 43.940 & 0.0000 & 118.79 & 0.0000 & 2.094 & 0.1505 & 2.336 & 0.1298 \\
\hline 2 July & 42.149 & 0.0000 & 59.369 & 0.0000 & 2.845 & 0.0943 & 6.6276 & 0.0130 \\
\hline 7 July & 28.152 & 0.0000 & 28.762 & 0.0000 & 66.225 & 0.0000 & 12.469 & 0.0016 \\
\hline 12 July & 31.000 & 0.0051 & 12.197 & 0.0022 & 13.089 & 0.0015 & 15.247 & 0.0298 \\
\hline
\end{tabular}

\section{DISCUSSION}

Argulus coregoni, which is usually found on salmonid fishes, can, nevertheless, grow and develop, reach maturity and reproduce on the roach Rutilus rutilus. However, mortality of parasites from the roach tanks was higher than in the tanks with rainbow trout. We observed that the roach in the tanks ingested some of the freeswimming parasites. This could be one of the reasons of higher mortality in the roach tanks. The ability of $A$. coregoni to complete its life cycle on roach as well as on rainbow trout suggests that there is no physiological or biochemical incompatibility between

the end of the exposure period of $2.5 \mathrm{~h}$ (Table 3), and these were removed from the experiment. Parasites attached faster to the rainbow trout $\left(t_{\mathrm{at}}\right.$, mean $\pm \mathrm{SD}=$ $17 \pm 20.4 \mathrm{~min})$ than to the roach $(44 \pm 43.7 \mathrm{~min})$ (Kruskal-Wallis ANOVA by ranks: $H[1, \mathrm{n}=81]=10.71$; $p=0.0011$ ). There was no significant difference in attachment rates between female and male argulids (females $37.0 \pm 37.5 \mathrm{~min}$ on roach, $13.1 \pm 13.7 \mathrm{~min}$ on rainbow trout; males $54.3 \pm 50.4$ min on roach, $20.5 \pm$ $25.6 \mathrm{~min}$ on rainbow trout) (Kruskal-Wallis ANOVA: $H$ $[1, \mathrm{n}=35]=1.16 ; \mathrm{p}=0.2807$ on roach; $H[1, \mathrm{n}=46]=$ $0.82, p=0.3638$ on rainbow trout).

Because of the low number of observed detachment events (Table 3 ), we pooled the data on male and female parasites when estimating the effect of host species, and the data on different host species when estimating the effect of parasite sex. Residence time on rainbow trout was significantly longer $\left(t_{\text {res }}\right.$ mean $\pm \mathrm{SD}$ $=11.8 \pm 1.66 \mathrm{~h}$ ) than on roach $(9.3 \pm 4.09 \mathrm{~h}$ ) (KruskalWallis ANOVA: $\mathrm{H}[1, \mathrm{n}=81]=13.39 ; \mathrm{p}=0.0003$ ). There was also a significant difference in the residence time between females $(11.6 \pm 1.67 \mathrm{~h})$ and males $(9.6 \pm$ $4.14 \mathrm{~h}$ ) (Kruskal-Wallis ANOVA: $\mathrm{H}[1, \mathrm{n}=81]=6.64$; $\mathrm{p}=0.010)$.

Table 3. Argulus coregoni. Number of males and females in the attachment-detachment experiments with rainbow trout Oncorhynchus mykiss and roach Rutilus rutilus. Observation period was $2.5 \mathrm{~h}$ in the attachment and $12 \mathrm{~h}$ in detachment experiments

\begin{tabular}{|lcccc|}
\hline \multirow{2}{*}{$\begin{array}{l}\text { No. of } \\
\text { parasites }\end{array}$} & \multicolumn{2}{c}{ Rainbow trout } & \multicolumn{2}{c|}{ Roach } \\
& Males & Females & Males & Females \\
\hline Released & 24 & 24 & 24 & 24 \\
Attached & 22 & 24 & 15 & 20 \\
Detached & 1 & 0 & 10 & 3 \\
\hline
\end{tabular}

the parasites and roach. After hatching, the growth rates of young parasites were the same on both hosts. Eventually, the growth of $A$. coregoni on rainbow trout became significantly faster than on roach. However, the observed size differences of the parasites on roach and rainbow trout were much less pronounced than for some other fish parasites, in which a high level of phenotypic plasticity has been found. For example, for the cestode Triaenophorus crassus, the weight of gravid individuals of the same age varied between 5.7 and $124 \mathrm{mg}$ (Shostak \& Dick 1987); in the nematode Raphidascaris acus, gravid females ranged from 0.7 to $61.2 \mathrm{mg}$ (Szalai \& Dick 1989). The ranges of fecundity among individuals of these 2 species are even greater. Fecundity is strongly correlated with body size in most animals, including parasites (Peters 1983). The mean size of $A$. coregoni females from roach $(n=17,10.00 \pm$ $0.10 \mathrm{~mm}$ ) was the same as that of females from trout $(\mathrm{n}=48,10.05 \pm 0.67 \mathrm{~mm})$ when the first egg clutches were laid. Thus, we would not expect differences in individual fecundity related to body size between $A$. coregoni females grown on rainbow trout and females grown on roach. Indeed, even a larger variation in female size (from 9 to $12 \mathrm{~mm}$ ) (H. Hakkinen et al. unpubl. data) did not result in significant changes in fecundity. Long-term fecundity response related to growth on different hosts needs to be studied.

Argulid females are usually reported to be larger than males (Kollatsch 1959, Shimura 1983, but see Hakalahti \& Valtonen 2003). However, the relationship between the size of males and females changed during ontogeny. Males grew faster at the beginning of ontogeny, but after attaining maturity at the size of 5 to $6 \mathrm{~mm}$ (Shimura 1983), the growth rate of females noticeably exceeded that of males. As a result, females grew larger 1 to $2 \mathrm{wk}$ before the egg laying. The observed ontogenetic decrease in the growth rate of 
males could be due to their shorter residence time on hosts. Similar dimorphism in behaviour was also found in Argulus foliaceus (Pasternak et al. 2000). More frequent detachment of males correspond to the findings of other authors (Kollatsch 1959, Stammer 1959), who noted a larger proportion of females on fish hosts, whereas free-swimming males were more numerous than free-swimming females. A male-biased sex ratio for A. coregoni sampled on fish (Oncorhynchus mykiss) in summer was recorded by Hakalahti \& Valtonen (2003). Outside the period of egg-laying, males, detaching from their host in search of mates, spend more energy to sustain their more active metabolism. Moreover, they have less time for feeding on the host and, consequently, less resources for growth.

The observed differences in the growth rate and size of Argulus coregoni reared on rainbow trout and roach was also related to differences in their residence time on the 2 species. At a size of $2 \mathrm{~mm}$, an ontogenetic shift in host choice occurred, with their initial preference for the brighter and more easily recognizable roach (Mikheev et al. 1998) changing to a highly pronounced preference for rainbow trout (Mikheev et al. 2004). This could be the main reason for their more frequent detachment from roach. Whatever the cause of this shift in preference, it resulted in lower fidelity of A. coregoni to the cyprinid host and thus in a reduction of time available for feeding. Bower-Shore (1940), who compared the growth of $A$. foliaceus on different species of fishes, suggested that the larger the host, the quicker the growth of the parasite. However, this was not the case in our study, as both hosts were of similar size.

The potential of Argulus coregoni to complete its life cycle on a cyprinid host has important ecological consequences: when the preferred salmonid hosts are not available, the parasite can use other fishes as alternative hosts (Holmes 1979), thus allowing A. coregoni a lower, but continuous recruitment, and ensuring the maintenance of the parasite population.

Although greater specialization on fewer host species is advantageous, it also links the fate of parasites to that of their hosts and can make highly host-specific parasites more prone to local extinction (Poulin 1996). Widening the spectrum of potentially available fish hosts when the main hosts are rare could be of particular importance for parasites inhabiting boreal waters with short productive periods and often low densities of fish populations.

Acknowledgements. We thank the staff of the farm in Central Finland where the experiments were conducted. Thanks are due to Z. Kabata and an anonymous referee for useful com-

Editorial responsibility: Wolfgang Körting,

Hannover, Germany ments and corrections. This study was supported by the SUNARE research program from the Academy of Finland and the Russian Foundation for Basic Research (grants 01-0448701 to A.P. and 02-04-48480 to V.M.).

\section{LITERATURE CITED}

Bower-Shore C (1940) An investigation of the common fish louse, Argulus foliaceus (Linn.). Parasitology 32:361-371

Combes C (1991) Ethological aspects of parasite transmission. Am Nat 138:866-880

Fry JD (1990) Trade-offs in fitness on different hosts: evidence from a selection experiment with a phytophagous mite. Am Nat 136:569-580

Hakalahti T, Valtonen ET (2003) Population structure and recruitment of the ectoparasite Argulus coregoni Thorell (Crustacea: Branchiura) on a fish farm. Parasitology 126:1-7

Holmes JC (1979) Parasite populations and host community structure. In: Nickol BB (ed) Host-parasite interfaces. Academic Press, New York, p 27-46

Kollatsch D (1959) Untersuchungen über die Biologie und Ökologie der Karpfenlaus (Argulus foliaceus L.). Zool Beitr 5:1-36

Lester RJG, Roubal FR (1995) Phylum Arthropoda. In: Woo PTK (ed) Fish diseases and disorders, Vol 1. Protozoan and metazoan Infections. CAB International, Wallingford, p 475-598

Mikheev VN, Valtonen ET, Rintamaki-Kinnunen P (1998) Host searching in Argulus foliaceus L. (Crustacea: Branchiura): the role of vision and selectivity. Parasitology 116:425-430

Mikheev VN, Pasternak AF, Valtonen ET (2004) Tuning host specificity during the ontogeny of a fish ectoparasite: behavioural responses to host-induced cues. Parasitol Res (in press)

Pasternak AF, Mikheev VN, Valtonen ET (2000) Life history characteristics of Argulus foliaceus L. (Crustacea: Branchiura) populations in Central Finland. Ann Zool Fen $37: 25-35$

Peters RH (1983) The ecological implications of body size. Cambridge University Press, Cambridge

Poulin R (1996) The evolution of life history strategies in parasitic animals. Adv Parasitol 37:107-134

Shimura S (1983) Seasonal occurence, sex ratio and site preference of Argulus coregoni Thorell (Crustacea: Branchiura) parasitic on cultured freshwater salmonids in Japan. Parasitology 86:537-552

Shostak AW, Dick TA (1987) Individual variability in reproductive success of Triaenophorus crassus Forel (Cestoda: Pseudophyllidae), with comments on use of the Lorenz curve and Gini coefficient. Can J Zool 65:2878-2885

Stammer J (1959) Beiträge zur Morphologie, Biologie und Bekämpfung der Karpfenläuse. Z Parasitenkd 19:135-208

Szalai AJ, Dick TA (1989) Differences in numbers and inequalities in mass and fecundity during the egg-producing period for Raphidoscaris acus (Nematoda: Anisakidae). Parasitology 98:489-495

Valtonen ET, Holmes JC, Koskivaara M (1997) Eutrophication, pollution, and fragmentation: effects on parasite communities in roach (Rutilus rutilus) and perch (Perca fluviatilis) in four lakes in central Finland. Can J Fish Aquat Sci 54:572-585

Submitted: July 8, 2003; Accepted: November 13, 2003

Proofs received from author(s): February 25, 2004 